\title{
PPE Supply Chain Needs Data Transparency and Stress Testing
}

Tinglong Dai, $P h D^{1,2}$, Ge Bai, $P h D, C P A^{1,3}$, and Gerard F. Anderson, $P h D^{3,4}$

'Johns Hopkins University, Carey Business School, Baltimore, USA; ${ }^{2} J o h n s$ Hopkins University, School of Nursing, Baltimore, USA; ${ }^{3}$ Johns Hopkins University, Bloomberg School of Public Health, Baltimore, USA; ${ }^{4}$ Johns Hopkins University, School of Medicine, Baltimore, USA.

J Gen Intern Med 35(9):2748-9

DOI: $10.1007 / \mathrm{s} 11606-020-05987-9$

(c) Society of General Internal Medicine 2020

$\mathrm{D}$ uring the ongoing COVID-19 pandemic, the USA is experiencing a severe shortage of personal protective equipment (PPE) that threatens care delivery and the safety of medical staff. ${ }^{1}$ In a normal year, the USA spends approximately $\$ 5$ billion on PPE, with imports constituting more than $20 \%$ of the supply. ${ }^{2}$ Specialized PPE is particularly dependent on imports. For example, an estimated $90 \%$ of N95 masks are imported, mostly from China. This heavy dependence on foreign-made specialized PPE makes its supply chain vulnerable and exposes health care workers and patients to substantial risks. When countries, states, cities, hospitals, and clinicians are all competing for the same limited international supply during the pandemic, the risks are escalated to crises that challenge public health and national health security. By some estimate, clinicians account for nearly $20 \%$ of the COVID-19-infected cases in the USA. ${ }^{3}$ This is in contrast to countries such as Singapore and South Korea where clinicians have been rarely infected due to sufficient domestically supplied PPE.

The current shortage of PPE in the USA, especially N95 masks, is predictable and preventable. Both the $2009 \mathrm{H} 1 \mathrm{~N} 1$ influenza pandemic and the 2014 Ebola virus epidemic exposed a shortage of domestically produced PPE. On February 25, 2020, Alex Azar, the Health and Human Services Secretary, informed Congress that at least 300 million N95 masks were required for the upcoming battle against coronavirus and there were only 30 million available in the Strategic National Stockpile. In spite of these and other warnings, the supply of PPE continues to be severely limited and dependent on international supply with devastating impact on clinicians treating COVID-19 patients.

The USA stands out as a developed economy — ranked No. 1 in health care spending ${ }^{4}$ - that failed to improve the availability of crucial PPE. Many other economies, in contrast, were able to successfully ramp up their production capacity

Received May 14, 2020

Accepted June 12, 2020

Published online June 30, 2020 of PPE within a short period of time. For example, a consortium of Taiwanese manufacturers built a daily capacity of 15 million masks, making Taiwan the second largest producer of medical masks in the world in a matter of weeks.

Supply chain management theory categorizes products into four types, depending on their internal value and external supply risks. The internal value captures the importance of the product to the mission, whereas the external supply risk measures "supply scarcity, pace of technology and/or materials substitution, entry barriers, logistics cost or complexity, and monopoly or oligopoly conditions." "High-value, highrisk product categories, such as N95 masks, are classified as strategic items and should be managed differently from the other product categories, including bottleneck items (low-value, high-risk), leverage items (high-value, low-risk), and noncritical items (low-value, low-risk). For strategic items, policymakers should focus on their long-term availability and the resiliency of supply chain by diversifying the supply base, conducting regular risk analysis, developing stress tests, and being prepared for the worst case.

A prerequisite is data transparency. In the USA, a paucity of data on the relevant members of the supply chain and where the PPE is actually produced has left the federal government, state and local governments, hospitals, physicians, and other PPE purchasers in the dark. Currently, PPE manufacturers - the three largest in the USA being 3M Company, Honeywell International Inc., and MSA Safety Inc.- are only required to report the locations of their manufacturing facilities to the Food and Drug Administration. Basic PPE supply chain data (e.g., the production quantity in each facility) is treated as confidential and not disclosed to any government agency, the public, or the companies' shareholders. We examined the past 5 years' financial disclosure of the three major PPE manufacturers and conducted an exhaustive search of more than 1,700 media reports about the PPE supply chain, published between January 14 and April 26, 2020, and found no basic supply chain data, including, for example, the exact domestic vs. foreign capacity of N95 masks.

The very first step Congress should take is to mandate publicly available data on the PPE supply chain, justified by PPE's strategic public health importance. At a minimum, all publicly traded PPE manufacturers operating in the USA should be required to disclose their production capacity and the percentage of PPE imported from facilities in each foreign 
country. Such disclosure can be included in Form 10-K, the publicly available annual report that all publicly traded firms must file with the Securities and Exchange Commission. The incremental burden for PPE manufacturers to file such disclosure is minimal, but the potential benefit to the public is substantial.

Publicly available PPE supply chain data makes it possible for federal and state governments, hospitals, physicians, and other stakeholders to assess the risk of PPE supply chain disruptions for each manufacturer and demand that the manufacturers take proactive actions to manage it. This may influence manufacturers' design decisions on their supply chain networks. The pressure from investors and consumers has caused many companies to change behavior on issues ranging from consumer privacy to climate change.

Besides transparency, Congress should require all major PPE manufacturers (for example, those with US market shares $>10 \%$ ) to undergo stress testing. The 2008 recession prompted regular stress testing of banks and yielded benefits: The banks are now more resilient and less likely to have inadequate capital during future economic crises. The ongoing COVID19 pandemic, in addition to significant morbidity and mortality impacts, has led to far greater US job losses than those recorded in the 2008 Recession. Stress tests would be critical to ensuring that PPE manufacturers can ramp up domestic production capacity within a reasonable period of time. ${ }^{6}$ Major PPE manufacturers, upon failing the stress test, would be required to rebalance their supply chains to maintain ample domestic capacity and reduce foreign dependency, especially dependence on nations with high risks to US national security. Federal and state governments should incorporate stress test results as the criteria for their stockpile procurement decisions. Hospitals, physicians, and other private purchasers would have the option to do the same.

Stress tests conducted at the manufacturer level alone are unlikely to be sufficient to maintain resilience of the US PPE supply chain. For example, nonwoven fibers, the key raw material for N95 masks, are exclusively manufactured in China, a significant vulnerability that has to be addressed beyond the scope of PPE manufacturers. The Department of Health and Human Services should conduct periodic review of the resilience of the complete PPE supply chain and identify vulnerabilities challenging its resilience. Such information would provide evidence-based guidance on how to guard the public against PPE shortage risks when the nation faces natural, intentional, or accidental biological threats.

If Congress mandates transparency and stress testing in the PPE supply chain, an increase in domestic PPE capacity, especially for strategic items such as N95 masks, is expected to occur. Beyond PPE, Congress may also consider identifying other critical medical supplies, such as essential prescription drugs, using national health security risk assessments, and creating similar policies to gradually reduce foreign dependency. These policies will be essential for the USA to improve the critical medical supply chain's readiness to meet a demand surge during future pandemics and biological or chemical warfare. This will also create manufacturing capacity, skilled human capital, technical know-how that form agile "industrial commons,", leading to broader prosperity and enhanced national security.

Acknowledgments: We thank Joshua Choe for his research assistance.

Corresponding Author: Ge Bai, PhD, CPA; Johns Hopkins University, Bloomberg School of Public Health, Baltimore, USA (e-mail: gbai@jhu.edu).

Funding Information Ge Bai and Gerard Anderson receive funding from Arnold Ventures.

\section{Compliance with Ethical Standards:}

Conflict of Interest: The authors declare that they do not have a conflict of interest.

\section{REFERENCES}

1. Livingston E, Desai A, Berkwits M. Sourcing Personal Protective Equipment During the COVID-19 Pandemic. JAMA. Published online March 28, 2020. https://doi.org/10.1001/jama.2020.5317

2. Personal Protective Equipment Manufacturing Industry in the US - Market Research Report. Published May 2020. Accessed May 12, 2020. https:// www.ibisworld.com/united-states/market-research-reports/personal-protective-equipment-manufacturing-industry/

3. CDCMMWR. Characteristics of Health Care Personnel with COVID-19 United States, February 12-April 9, 2020. MMWR Morb Mortal Wkly Rep. 2020;69. https://doi.org/10.15585/mmwr.mm6915e6

4. Anderson GF, Hussey P, Petrosyan V. It's Still The Prices, Stupid: Why The US Spends So Much On Health Care, And ATribute To Uwe Reinhardt. Health Affairs. 2019;38(1):87-95. https://doi.org/10.1377/hlthaff.2018. 05144

5. Kraljic P. Purchasing must become supply management. Harvard Business Review. 1983;61(5): 109-117.

6. Simchi-Levi D, Simchi-Levi E. We Need a Stress Test for Critical Supply Chains. Harvard Business Review. Accessed April 28, 2020. https://hbr. org/2020/04/we-need-a-stress-test-for-criticalsupply-chains

7. Pisano GP, Shih WC. Producing Prosperity: Why America Needs a Manufacturing Renaissance. Harvard Business Press; 2012.

Publisher's Note: Springer Nature remains neutral with regard to jurisdictional claims in published maps and institutional affiliations. 